\title{
A New Method for Evaluation of Mechanical Properties of Glass/Epoxy Composites at Low Temperatures
}

\author{
M. M. Shokrieh, ${ }^{a}$ M. A. Torabizadeh, ${ }^{b, 1}$ and A. Fereidoon ${ }^{\mathrm{c}}$ \\ ${ }^{a}$ Iran University of Science and Technology, Tehran, Iran \\ ${ }^{\mathrm{b}}$ University of Applied Science and Technology, Branch of Khorasan Razavi, Mashhad, \\ Iran \\ ${ }^{c}$ University of Semnan, Semnan, Iran \\ 1 Torabizadeh@yahoo.com
}

УдК 539.4

\section{Новый метод оценки механических свойств стеклоэпоксидных композитов при низких температурах}

\begin{abstract}
М. М. Шокри ${ }^{a}$, М. А. Торабизаде ${ }^{\sigma, 1}$, А. Ферейдун ${ }^{\text {в }}$
${ }^{\text {a } И р а н с к и и ̆ ~ у н и в е р с и т е т ~ н а у к и ~ и ~ т е х н о л о г и и, ~ Т е г е р а н, ~ И р а н ~}$

${ }^{\sigma}$ Университет прикладной науки и технологии, Провинция Хорасан Разави, Мешхед, Иран

${ }^{\text {в } У н и в е р с и т е т ~ г . ~ С е м н а н а, ~ И р а н ~}$

Для расчета прочности однонаправленного композита при различных видах нагружения в условиях комнатной температуры $и-60^{\circ} \mathrm{C}$ использованы аналитические модели, учитываюшие микромеханические характеристики композитов. В отличие от стандартных методов, базирующихся на результатах испьтаний образиов из однонаправленного композита, в данной работе измеряются микромеханические характеристики стекловолокон и эпоксидной матрииы. С помощью разных аналитических моделей выполнен расчет четырех различных модулей упругости и характеристик прочности при комнатной температуре и $-60^{\circ} \mathrm{C}$. C целью верификачии результатов расчета проведены экспериментальные исследования. Показано, что наилучший расчет модулей упругости однонаправленного композита при комнатной и низкой температурах обеспечивает применение упругой модели. Получено хорочее соответствие между расчетными и экспериментальными данными по механическим характеристикам этого материала при исследованных температурах.
\end{abstract}

Ключевые слова: механические характеристики, микромеханические модели, низкая температура, прогнозирование, однонаправленный композит.

\section{Notation}

$E_{1}, E_{2}-$ longitudinal and transverse Young moduli of unidirectional composites, respectively

$G_{12} \quad-$ shear modulus of unidirectional composites

$E_{f}, E_{m}-$ fiber longitudinal and matrix Young moduli, respectively 


\begin{tabular}{ll}
\hline$G_{f}, G_{m}$ & - fiber and matrix shear moduli, respectively \\
$V_{f}, V_{m}$ & - fiber and matrix volume fractions, respectively \\
$v_{12}$ & - major Poisson's ratio of unidirectional composites \\
$v_{f}, v_{m}$ & - Poisson's ratios of fiber and matrix, respectively \\
$\sigma_{f, u}, \sigma_{m, u}$ & - fiber and matrix tensile strengths, respectively \\
$\sigma_{m, u}^{c}$ & - matrix compressive strength \\
$\tau_{f, Y}, \tau_{m, Y}$ & - shear yield stresses of fiber and matrix, respectively \\
$X_{t}, X_{c}$ & - longitudinal tensile and compressive strengths, respectively \\
$Y_{t}, Y_{c}$ & - transverse tensile and compressive strengths, respectively \\
$S$ & - shear strength of unidirectional composites \\
$\varepsilon_{f}, \varepsilon_{m}$ & - fiber and matrix tensile strains, respectively \\
$\alpha_{f}, \alpha_{m}$ & - coefficients of thermal expansion of fiber and matrix, respectively
\end{tabular}

Introduction. One of the persistent difficulties in the design and analysis of composites is prediction of laminate fracture under uniaxial and/or combined loading by using either unidirectional (UD) composite data or micromechanics with pristine constituent material properties. However, in contrast to isotropic materials, experimental evaluation of these data is quite costly and time consuming because they are functions of several variables: the individual constituents of the composite material, fiber volume fraction, stacking sequence of plies, processing, etc. Thus, the need and motivation for developing analytical models to find these parameters are very important. The difficulty of prediction of laminate's strength has been compounded multiply by the availability of many and diverse failure criteria. It became apparent, therefore, that some kind of formalized comparisons between various failure theories with measured data would be instructive and very useful. Micromechanical models to predict the mechanical behavior of UD composites have been studied by several authors [1-7].

Carbajal and Mujika [8] have determined the compressive strength of unidirectional composites by three-point bending tests. Unidirectional carbon/ epoxy composites T6T/F593 from Hexcel Composites are tested by three-point bending with different thicknesses and spans. Liang et al. [1] studied the ultimate strength of continuous composite beams in combined bending and shear. They developed a three-dimensional finite element model which was in good agreement with experimental results. Huang [2] illustrated a micromechanical prediction of ultimate strength of transversely isotropic fibrous composite. The biggest difference of his theory, relative to those existing micromechanics models, was that the constituent nonlinear deformation had been taken into account reasonably. They found good correlation between the predicted strengths and available experimental data. Naik and Kumar [3] evaluated and compared some of the existing models proposed for predicting the compressive strength of UD composites along the fiber direction. They found that Lo-Chim [9] model gave good results as it was correlated with the same set of experimental results for obtaining experimental parameters. Camanho et al. [10] proposed a new analytical closed-form model to predict the in situ shear strength of composite laminates as a function of ply thickness and location. Hatta et al. [11] reviewed various strengths of carbon- 
carbon composites. The topics reviewed included tensile, shear, compressive and fatigue strengths, as well as fiber/matrix interfacial strength of $\mathrm{C} / \mathrm{Cs}$. Sun and Jun [4] considered the effect of fiber misalignment and non-linear behavior of the matrix on fiber microbuckling and the compressive strength of a unidirectional fiber composite. Their results showed reasonable correlation with available experimental data. Wilczynski [5] described a model to predict the mechanical properties of unidirectional fibrous composites in longitudinal compression. He illustrated an analytical solution for both straight and initially curved reinforcing fibers. He found that his results showed 30\% higher values than experimental ones. Huang [6] simulated the overall thermal-mechanical properties of a fibrous composite beyond of an elastic deformation range using a recently developed micromechanics model (the bridging model). King et al. [7] presented a method to estimate the influence of the matrix and the interfacial bond strength itself on the composite shear strength for a given fiber/matrix composite. Analytical prediction of these effects has been achieved using a finite element micromechanics model. Numerical results generated using this model have shown a close fit with experimental data.

The aim of the present paper is to use micromechanical properties of composite at room temperature and $-60^{\circ} \mathrm{C}$ to predict mechanical properties of UD composites. This includes of four elastic moduli and strengths of laminated composites. By a set of experimental tests, mechanical properties of glass fiber and epoxy matrix at room temperature and $-60^{\circ} \mathrm{C}$ are determined. Then by using different proposed micromechanics models, full characterization of UD composite is performed.

Micromechanical Properties. Before modeling the nine parameters of unidirectional composites (including four elastic moduli and five strengths), micromechanical properties of glass fiber and epoxy matrix should be determined. An experimental program is conducted to characterize the fiber and resin. The specimens are tested to failure at room and low temperatures. Figures 1 and 2 show typical test specimens of fiber and matrix at room temperature before and after tensile test, respectively. All tests were conducted under displacement control condition using an Instron 5582 machine adaptable for cryogenic service by an environmental chamber. The displacement rate was $2 \mathrm{~mm} / \mathrm{min}$. Environmental chamber has the ability to cool down the temperature to $-196^{\circ} \mathrm{C}$ by evaporating liquid cryogenic nitrogen. During the tests, a pressurizing device is used to control the cooling time from room temperature to $-60^{\circ} \mathrm{C}$ and maintain an evaporating pressure of $152 \mathrm{kPa}$. Figure 3 shows experimental equipment for mechanical testing at both room and low temperatures.

The measured properties are summarized in Table 1.

As shown in Table 1, micromechanical properties of composite (both fiber and matrix) change with decreasing temperature. However, the difference is that changes in mechanical properties of epoxy matrix are much higher than those of glass fiber. For example, with temperature reduction longitudinal stiffness of fiber increases $34 \%$ whereas that for matrix is about $80 \%$. The respective increases in the tensile strength of fiber and matrix at $-60^{\circ} \mathrm{C}$ are 14 and $40 \%$, respectively. Therefore, the role of matrix in changing the mechanical properties of composite is stronger than that of glass fiber. 
M. M. Shokrieh, M. A. Torabizadeh, and A. Fereidoon

$\mathrm{T}$ a b 1 e 1

Experimental Material Properties of Glass Fiber and Epoxy Matrix

at Room Temperature and $-60^{\circ} \mathrm{C}$

\begin{tabular}{|c|c|c|c|c||}
\hline \multirow{2}{*}{$\begin{array}{c}\text { Mechanical } \\
\text { properties }\end{array}$} & \multicolumn{2}{|c|}{ Glass fiber } & \multicolumn{2}{c||}{ Epoxy matrix } \\
\cline { 2 - 5 } & $23^{\circ} \mathrm{C}$ & $-60^{\circ} \mathrm{C}$ & $23^{\circ} \mathrm{C}$ & $-60^{\circ} \mathrm{C}$ \\
\hline$E, \mathrm{GPa}$ & 45.94 & 65.40 & 2.30 & 4.20 \\
\hline$G, \mathrm{GPa}$ & 18.40 & 23.17 & 0.88 & 1.40 \\
\hline$\varepsilon, \%$ & 3.0 & 2.0 & 6.5 & 5.0 \\
\hline$\sigma_{u}, \mathrm{MPa}$ & 1100.0 & 1260.0 & 150.2 & 210.5 \\
\hline$\tau_{u}, \mathrm{MPa}$ & 35.00 & 40.07 & 34.00 & 48.10 \\
\hline$v$ & 0.2 & - & 0.3 & - \\
\hline$\alpha \cdot 10^{-6},\left({ }^{\circ} \mathrm{C}\right)^{-1}$ & 5 & - & 62 & - \\
\hline$V$ & 0.55 & 0.55 & 0.45 & 0.45 \\
\hline
\end{tabular}

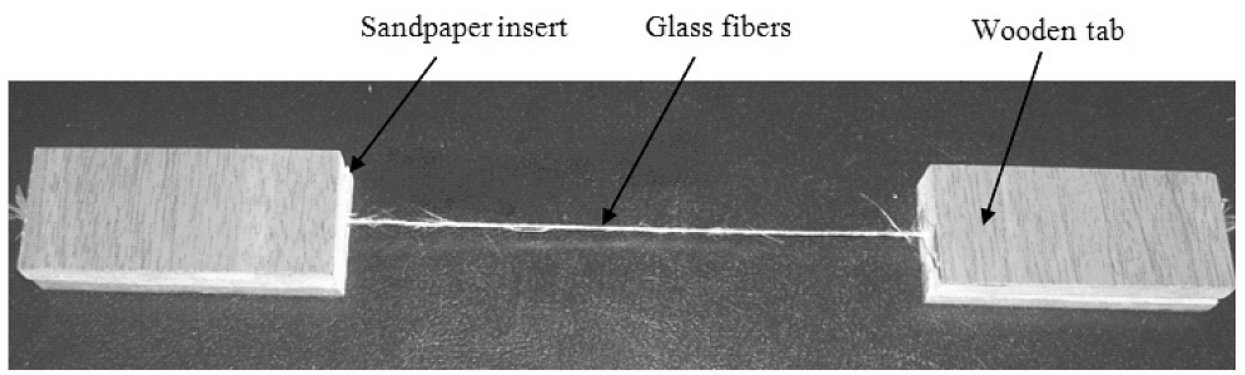

$a$

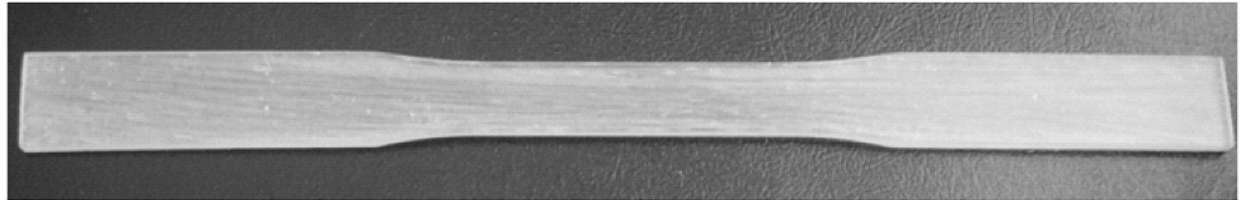

$b$

Fig. 1. Typical test specimens for glass fibers (a) and epoxy resin ML506 (b).

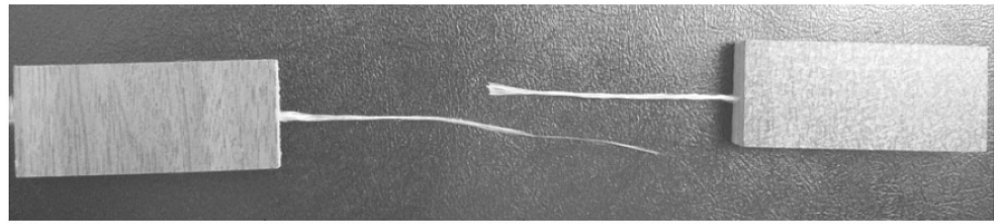

$a$

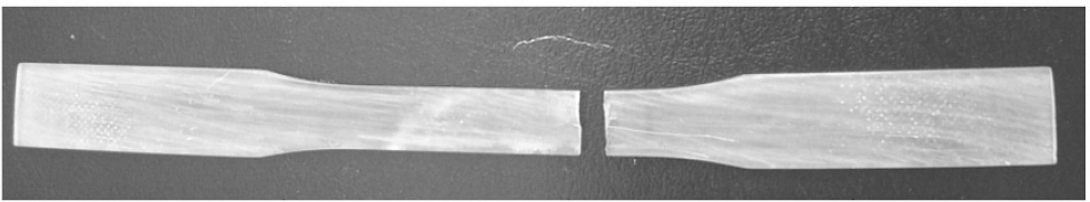

$b$

Fig. 2. Typical tested specimens for glass fibers (a) and epoxy resin ML506 (b) at room temperature. 


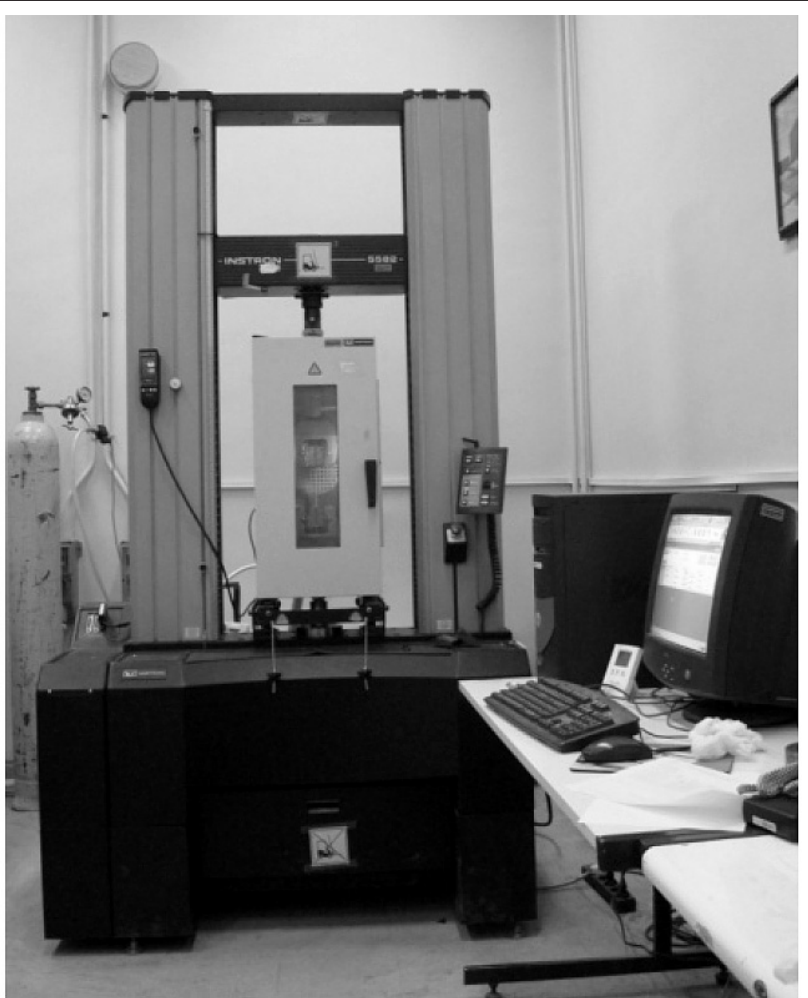

Fig. 3. Experimental set up for mechanical testing at room and low temperatures.

Four Elastic Moduli. In this section, different available micromechanics models for prediction of elastic moduli of UD composites are illustrated. To prevent repeating, the explication of derivation of relations is not discussed here [12].

Strength of Material Approach.* Longitudinal Young Modulus. This method has some assumptions to model the behavior of UD composites, such as: perfect bond between fibers and matrix; elastic moduli, diameter and space between fibers; continuous and parallel fibers; fibers and matrix are linearly elastic and the composite is free of voids. By these assumptions, this method illustrates the following relation:

$$
E_{1}=E_{f} V_{f}+E_{m} V_{m}
$$

Transverse Young Modulus. In the same manner, the following equation is illustrated by this method for this elastic modulus:

$$
\frac{1}{E_{2}}=\frac{V_{f}}{E_{f}}+\frac{V_{m}}{E_{m}} .
$$

In-Plane Shear Modulus. According to shear deformation and stresses in fiber and matrix, in-plane shear modulus of UD composites can be predicted as

\footnotetext{
* Rule of mixture.
} 


$$
\frac{1}{G_{12}}=\frac{V_{f}}{G_{f}}+\frac{V_{m}}{G_{m}} .
$$

Major Poisson's Ratio. The major Poisson's ratio is defined as the negative of the ratio of the normal strain in the transverse direction to the normal strain in the longitudinal direction, when a normal load is applied in the longitudinal direction. Thus it can be expressed as

$$
v_{12}=v_{f} V_{f}+v_{m} V_{m}
$$

Semi-Empirical Models. Due to some difficulties in previous method, semiempirical models have been developed for design purposes. The most useful of these models include those of Halpin and Tsai [12] because they can be used over a wide range of elastic properties and fiber volume fractions.

Longitudinal Young Modulus. The Halpin-Tsai equation for the longitudinal Young modulus is the same as that obtained through the strength of materials approach.

Transverse Young Modulus. The transverse Young modulus in this model is given by

$$
\frac{E_{2}}{E_{m}}=\frac{1+\xi \eta V_{f}}{1-\eta V_{f}},
$$

where

$$
\eta=\frac{\left(E_{f} / E_{m}\right)-1}{\left(E_{f} / E_{m}\right)+\xi} .
$$

The term $\xi$ is called the reinforcing factor and depends on fiber geometry, packing geometry and loading conditions. Halpin and Tsai obtained the value of the reinforcing factor by elastic solutions for a square array equal to 2 .

In-Plane Shear Modulus. The Halpin-Tsai equation for in-plane shear modulus is

$$
\frac{G_{12}}{G_{m}}=\frac{1+\xi \eta V_{f}}{1-\eta V_{f}},
$$

where

$$
\eta=\frac{\left(G_{f} / G_{m}\right)-1}{\left(G_{f} / G_{m}\right)+\xi} .
$$

The value of $\xi=1$ for circular fibers in a square array gives reasonable results only for fiber volume fractions of up to 50\%. Hewitt and Malherbe [12] suggested choosing a function:

$$
\xi=1+40 V_{f}^{10}
$$


Major Poisson's Ratio. The Halpin-Tsai equation for the major Poisson's ratio is the same as that obtained using the strength of materials approach.

Elasticity Approach. In addition to the two previous models, expressions for the elastic moduli based on elasticity are also available. Elasticity accounts for equilibrium of forces, compatibility and Hooke's law relationship in three dimensions, whereas the two previous methods were not satisfy these simultaneously.

Longitudinal Young Modulus. This model evaluates the longitudinal Young modulus as follows:

$$
\begin{gathered}
E_{1}=E_{f} V_{f}+E_{m}\left(1-V_{f}\right)-2 E_{m} E_{f} V_{f}\left(v_{f}-v_{m}\right)^{2}\left(1-V_{f}\right) \\
\times\left[E_{f}\left(2 v_{m}^{2} V_{f}-v_{m}+V_{f} v_{m}-V_{f}-1\right)\right. \\
\left.+E_{m}\left(-1-2 v_{f}^{2} V_{f}+v_{f}-V_{f} v_{f}+2 v_{f}^{2}+V_{f}\right)\right]^{-1} .
\end{gathered}
$$

Although the preceding expression can be written in a compact form by using definitions of shear and bulk modulus of the material, this is not discussed here. Note that the first two terms of Eq. (10) represent the mechanics of materials approach result given by Eq. (1).

Transverse Young Modulus. This model yields an exact solution for the transverse shear modulus. However, the transverse Young modulus can be found as follows:

$$
E_{2}=2\left(1+v_{23}\right) G_{23},
$$

where $G_{23}$ and $v_{23}$ are transverse shear and Poisson's ratio that is discussed in detail in Appendix.

In-Plane Shear Modulus. The shear modulus by elastic solution can be found as following:

$$
G_{12}=G_{m} \frac{G_{f}\left(1+V_{f}\right)+G_{m}\left(1-V_{f}\right)}{G_{f}\left(1-V_{f}\right)+G_{m}\left(1+V_{f}\right)} .
$$

Major Poisson's Ratio. This elastic modulus of UD composite is calculated in this model by the following equation:

$$
\begin{gathered}
v_{12}=v_{f} V_{f}+v_{m}\left(1-V_{f}\right)-V_{f} V_{m}\left(v_{f}-v_{m}\right) \\
\times\left(2 E_{f} v_{m}^{2}+v_{m} E_{f}-E_{f}+E_{m}-E_{m} v_{f}-2 E_{m} v_{f}^{2}\right) \\
\times\left[E_{f}\left(2 v_{m}^{2} V_{f}-v_{m}+V_{f} v_{m}-V_{f}-1\right)\right. \\
\left.+E_{m}\left(-1-2 v_{f}^{2} V_{f}+v_{f}-V_{f} v_{f}+2 v_{f}^{2}+V_{f}\right)\right]^{-1} .
\end{gathered}
$$


Strengths of UD Composites. In this section, method of evaluation of strength from the individual properties of the fiber and matrix by using different models is shown. The strength parameters for a UD lamina are much harder to predict than the stiffnesses because the strengths are more sensitive to the material and geometric non-homogeneities, fiber-matrix interface, fabrication process and environmental conditions. Several theoretical and empirical models are available for some of the strength parameters.

Longitudinal Tensile Strength. A simple mechanics of material approach model is applied with some basic assumptions such that fiber and matrix are isotropic, homogeneous and linearly elastic and the failure strain for the matrix is higher than that of fiber (in the case of polymeric matrix composites). By these assumptions, the ultimate strength of the composite in longitudinal direction is predicted as

$$
X_{t}=\sigma_{f, u} V_{f}+\varepsilon_{f, u} E_{m}\left(1-V_{f}\right) .
$$

Because the fibers carry most of the load in polymeric matrix composites, it is assumed that, when the fibers fail at the strain of $\varepsilon_{f}$, the whole composite fails.

Longitudinal Compressive Strength. The model used for calculating the longitudinal tensile strength for a unidirectional lamina cannot also be used for its longitudinal compressive strength because the failure modes are different. Three typical failure modes may occur: Fracture of matrix and/or fiber-matrix bond due to tensile strains in the matrix and/or bond; microbuckling of fibers in shear; extensional mode and shear failure of fibers. Based on these three modes, compressive strength of UD composites can be as follows:

Ultimate Tensile Strains in Matrix Failure Mode. Using the maximum strain failure theory, if the transverse strain exceeds the ultimate transverse tensile strain, the lamina is considered to have failed in the transverse direction. Thus

$$
X_{c}=\frac{E_{1}\left(\varepsilon_{2}^{t}\right)_{u}}{v_{12}} \text {. }
$$

However, for the value of $\left(\varepsilon_{2}^{t}\right)_{u}$ one can use the empirical formula,

$$
\left(\varepsilon_{2}^{t}\right)_{u}=\varepsilon_{m}\left(1-V_{f}^{1 / 3}\right)
$$

or the mechanics of materials formula,

$$
\left(\varepsilon_{2}^{t}\right)_{u}=\varepsilon_{m}\left[\frac{d}{s}\left(\frac{E_{m}}{E_{f}}-1\right)+1\right] .
$$

In the above relation, $d$ is diameter of the fibers and $s$ is center-to-center spacing between the fibers. For circular fibers in a square array,

$$
\frac{d}{s}=\left(\frac{4 V_{f}}{\pi}\right)^{1 / 2}
$$


Shear/Extensional Fiber Microbuckling Failure Mode. Local buckling models for calculating longitudinal compressive strengths have been developed. Since these results are based on advanced topics, only the final expressions are given:

$$
X_{c}=\min \left[S_{1}, S_{2}\right]
$$

where

$$
\begin{gathered}
S_{1}=2\left[V_{f}+\left(1-V_{f}\right) \frac{E_{m}}{E_{f}}\right] \sqrt{\frac{V_{f} E_{m} E_{f}}{3\left(1-V_{f}\right)}}, \\
S_{2}=\frac{G_{m}}{1-V_{f}} .
\end{gathered}
$$

This model has been introduced by Rosen [13].

Shear Stress Failure of Fibers Mode. A unidirectional composite may fail due to direct shear failure of fibers. In this case, based on the rule of mixtures, compressive strength of the unidirectional composite is as follow:

$$
X_{c}=2\left[\tau_{f, Y} V_{f}+\tau_{m, Y} V_{m}\right]
$$

Lo-Chim Model. Lo and Chim [9] proposed a model that is based on the fact that compression failure takes place by local microbuckling of fibers as opposed to the buckling of the entire length of the fiber. Buckling load of a simply supported Timoshenko beam was obtained using the energy balance principle. The beam properties were replaced by the composite properties. For glass/epoxy composites the relation is

$$
X_{c}=\frac{G_{12}}{1.5+12[6 / \pi]^{2}\left[\frac{G_{12}}{E_{1}}\right]} .
$$

Budiansky Model. Budiansky [14] unified Rosen and Argon formula for elastic-ideally plastic composites. The expression given by Budiansky is

$$
X_{c}=\frac{G_{12}}{1+\bar{\phi} / \varepsilon_{m}} \text {. }
$$

Here $G_{12}$ is defined as the effective longitudinal shear modulus of the composite, given by right-hand term of Rosen Eq. (21). Budiansky and Fleck [15] plotted the results of various researchers as $X_{c}$ vs. $G_{12}$ graph for different $\bar{\phi} / \varepsilon_{m}$ values. The data fell well below the elastic kinking line, and were consistent with their equation for a range of values of $\bar{\phi} / \varepsilon_{m}$ near 4 .

Wilczynski Model. This model predicts the compressive strength of UD composites based on failure mode of laminate as [5],

$$
X_{c}=\min \left[S_{1}, S_{2}, S_{3}\right] \text {, }
$$


where

$$
\begin{aligned}
& S_{1}=\sigma_{m, u}\left(1-V_{f}+\xi V_{f}\right), \\
& S_{2}=\frac{\sigma_{f, u}}{\zeta}\left(1-V_{f}+\xi V_{f}\right), \\
& S_{3}=\frac{R_{c}}{\zeta}\left(1-V_{f}+\zeta V_{f}\right) .
\end{aligned}
$$

In the above equations, $\zeta=E_{f} / E_{m}$ and $R_{c}$, critical microbuckling load, can be calculated as

$$
R_{c}=\sqrt{8 E_{m} E_{f} \frac{1-V_{m}}{1+V_{m}}} .
$$

Transverse Tensile Strength. An expression of mechanics of material approach model for finding the transverse tensile strength of a unidirectional lamina is given by $[12]$ :

$$
Y_{t}=E_{2}\left(\varepsilon_{2}^{t}\right)_{u}
$$

where

$$
\left(\varepsilon_{2}^{t}\right)_{u}=\left[\frac{d}{s} \frac{E_{m}}{E_{f}}+\left(1-\frac{d}{s}\right)\right] \varepsilon_{m} .
$$

The preceding expression assumes that the fiber is perfectly bonded to the matrix. If the adhesion between the fiber and matrix is poor, the composite transverse strength will be further reduced.

Transverse Compressive Strength. Equation (30), which was developed for evaluating transverse tensile strength, can be used to find the transverse compressive strengths of a lamina. The actual compressive strength is again lower due to imperfect fiber/matrix interfacial bond and longitudinal fiber splitting. Using compressive parameters in Eq. (30),

$$
Y_{c}=E_{2}\left(\varepsilon_{2}^{c}\right)_{u},
$$

where

$$
\left(\varepsilon_{2}^{c}\right)_{u}=\left[\frac{d}{s} \frac{E_{m}}{E_{f}}+\left(1-\frac{d}{s}\right)\right] \varepsilon_{m}^{c},
$$

$\varepsilon_{m}^{c}$ is the ultimate compressive failure strain of matrix, which is calculated from Hooke's law.

In-Plane Shear Strength. Strength of Material Approach. The procedure for finding the ultimate shear strength for a unidirectional lamina is using a mechanics of material approach as follows: 


$$
S=G_{12}\left[\frac{d}{s} \frac{G_{m}}{G_{f}}+\left(1-\frac{d}{s}\right)\right]\left(\gamma_{12}\right)_{m, u},
$$

where $\left(\gamma_{12}\right)_{m, u}$ is the ultimate shearing strain of the matrix, which is calculated from Hooke's law.

Tsai Model. Based on the Tsai model [16], the shear strength can be studied using the following equation,

$$
S=\frac{1+v_{f}\left(1 / \eta_{s}-1\right)}{K_{m, s}} \tau_{m},
$$

where

$$
\eta_{s}=\frac{1}{2}\left(1+\frac{G_{m}}{G_{f}}\right)
$$

and $K_{m, s}$ is matrix stress concentration factor in shear. An exact determination of $K_{m, s}$ is difficult because the behavior of matrix is nonlinear near failure. However, if the matrix is ductile, stress concentration can be assumed to be unity.

King Model. King et al. [7] predicted the in-plane shear strength of UD composites by the following expression,

$$
S=\frac{E_{2} \varepsilon_{m}}{\left[1+\left(\frac{E_{2} \varepsilon_{m}}{\sigma_{m, u}}\right)^{n}\right]^{1 / n}} .
$$

With some experimental evaluation, they found that parameter $n$ can be assumed equal to 2 for glass-epoxy composites.

Results and Discussion. Four Elastic Moduli. A comparison of the four elastic moduli using the mechanics of materials approach, Halpin-Tsai equations, and elastic models with experimental data points performed with fiber volume fraction of $55 \%$, for glass fiber/epoxy matrix composites, which their micromechanical properties are listed in Table 1 is showed in Figs. 4-7. All data in the following figures are plotted for room temperature.

As shown in above figures, the mechanics of material approach predicts the lower bound of all four elastic moduli at room temperature, while the Halpin-Tsai model estimates the upper bound in each elastic modulus. Among all applied models, elastic solution has the best fit with available experimental data for fiber volume fraction $55 \%$ at room temperature and $-60^{\circ} \mathrm{C}$. Tables 2 and 3 compare the predicted values for elastic moduli and those obtained from experimental tests at room temperature and $-60^{\circ} \mathrm{C}$, respectively.

Strengths of UD Composites. By employing described methods for predicting the five strengths of a unidirectional composite with micromechanical properties of glass fiber/epoxy matrix at room temperature and $-60^{\circ} \mathrm{C}$, strengths of UD composites can be estimated. Tables 4 and 5 illustrate the estimated values for five 
$\mathrm{T}$ a b 1 e 2

Comparison of Predicted Elastic Moduli with Experimental Data at Room Temperature

\begin{tabular}{||l|c|c|c|c||}
\hline \multicolumn{1}{|c|}{ Method } & $E_{1}, \mathrm{GPa}$ & $E_{2}, \mathrm{GPa}$ & $G_{12}, \mathrm{GPa}$ & $v_{12}$ \\
\hline Rule of mixture [12] & 21.43 & 4.74 & 1.84 & 0.275 \\
\hline Halpin-Tsai [12] & 21.43 & 8.13 & 2.71 & 0.275 \\
\hline Elastic model [12] & 21.44 & 6.54 & 2.63 & 0.266 \\
\hline Experimental & 19.94 & 5.83 & 2.11 & 0.244 \\
\hline
\end{tabular}

$\mathrm{T}$ a b 1 e 3

Comparison of Predicted Elastic Moduli with Experimental Data at $-60^{\circ} \mathrm{C}$

\begin{tabular}{||l|c|c|c|c||}
\hline \multicolumn{1}{|c|}{ Method } & $E_{1}, \mathrm{GPa}$ & $E_{2}, \mathrm{GPa}$ & $G_{12}, \mathrm{GPa}$ & $v_{12}$ \\
\hline Rule of mixture [12] & 30.03 & 8.47 & 2.89 & 0.275 \\
\hline Halpin-Tsai [12] & 30.03 & 13.78 & 4.16 & 0.275 \\
\hline Elastic model [12] & 30.04 & 10.44 & 4.06 & 0.266 \\
\hline Experimental & 28.65 & 11.03 & 4.21 & 0.244 \\
\hline
\end{tabular}

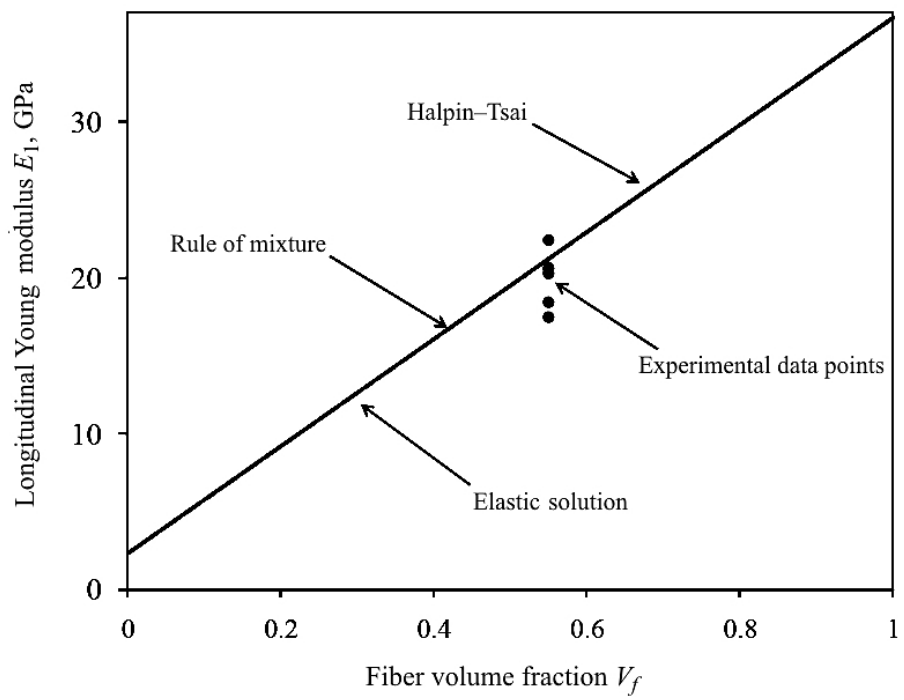

Fig. 4. Theoretical values of longitudinal Young modulus as a function of fiber volume fraction compared with experimental values for unidirectional glass/epoxy lamina at room temperature.

strengths of composite in comparison with experimental evaluated values at room temperature and $-60^{\circ} \mathrm{C}$, respectively.

As is evident from the above Tables, some analytical models for predicting the compressive strengths of UD lamina fail to match the experimental results. Several factors may contribute to this discrepancy, including: irregular spacing of fibers causing premature failure in matrix-rich area; less than perfect bonding between the fibers and the matrix and poor alignment of fibers. In addition, there is controversy concerning the techniques used in measuring compressive strengths. Moreover, predicting transverse tensile strength of UD lamina is quite complicated. Under a transverse tensile load, factors other than the individual properties of the 


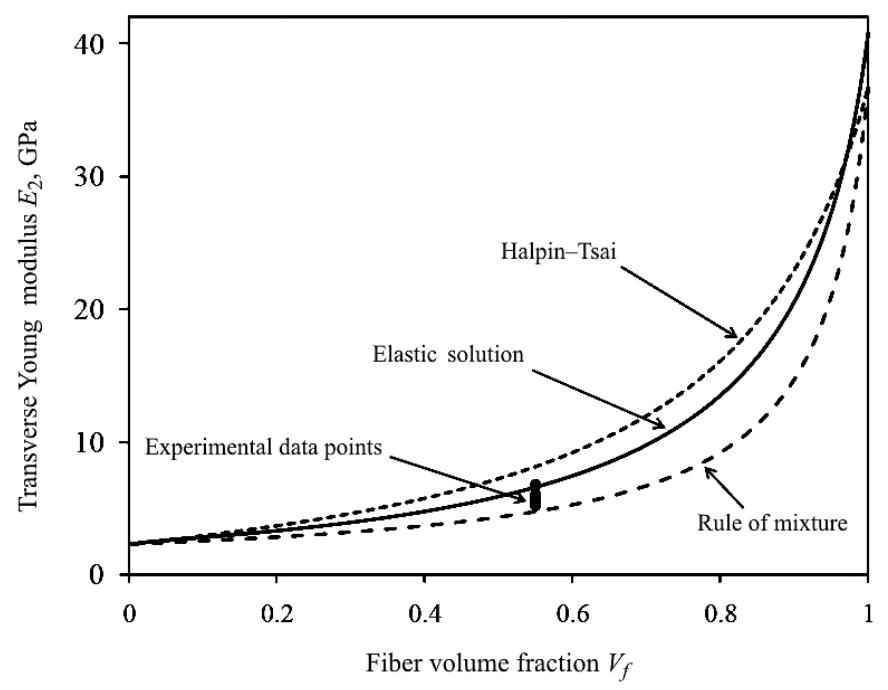

Fig. 5. Theoretical values of transverse Young modulus as a function of fiber volume fraction compared with experimental values for unidirectional glass/epoxy lamina at room temperature.

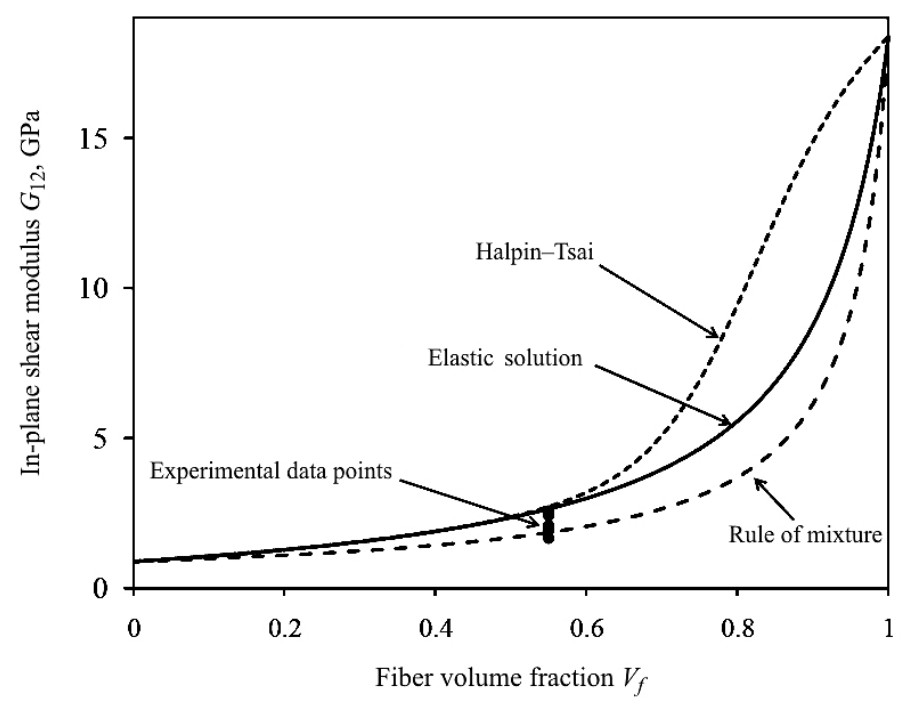

Fig. 6. Theoretical values of in-plane shear modulus as a function of fiber volume fraction compared with experimental values for unidirectional glass/epoxy lamina at room temperature.

fiber and matrix are important. These include the bond strength between the fiber and the matrix, the presence of voids and the presence of residual stresses due to thermal expansion mismatch between the fibers and matrix. The prediction of the ultimate shear strength is complex. Similar parameters such as weak interface, the presence of voids and Poisson's ratio mismatch, make modeling quite complex. The above results show that by imposing some errors, micromechanical models based on mechanical properties of fiber and matrix can be used instead of experimental evaluation of mechanical properties of UD composites at room temperature and $-60^{\circ} \mathrm{C}$. By this method, time consuming and costly tests on UD composites are eliminated, and simple characterization tests on fiber and matrix are only needed. 


T a b 1 e 4
Comparison of Predicted Strengths with Experimental Data at Room Temperature
\begin{tabular}{||c|c|c|c||}
\hline \multicolumn{2}{|c|}{ Strengths of composites } & Theoretical models (MPa) & Experimental results (MPa) \\
\hline Longitudinal tensile strength $\left(X_{t}\right)$ & Eq. (14) & 636.05 & 700.11 \\
\hline Transverse tensile strength $\left(Y_{t}\right)$ & Eq. (30) & 91.78 & 69.85 \\
\hline Transverse compressive strength $\left(Y_{c}\right)$ & Eq. (32) & 58.56 & 122.12 \\
\hline Longitudinal compressive strength & Eqs. (15, 19, 22) & 75.90 & 570.37 \\
$\left(X_{c}\right)$ & Lo-Chim (Eq. 23) & 382.86 & \\
& Budiansky (Eq. 24) & 391.10 & \\
& Wilczynski (Eq. 25) & 636.05 & \\
\hline In-plane shear strength $(S)$ & Eq. (34) & 20.71 & \\
& Tsai (Eq. 35) & 50.99 & \\
\hline & King (Eq. 37) & 105.89 & \\
\hline
\end{tabular}

T a b 1 e 5

Comparison of Predicted Strengths with Experimental Data at $-60^{\circ} \mathrm{C}$

\begin{tabular}{||l|c|c|c||}
\hline \multicolumn{1}{|c|}{ Strengths of composites } & \multicolumn{2}{c|}{ Theoretical models (MPa) } & Experimental results (MPa) \\
\hline Longitudinal tensile strength $\left(X_{t}\right)$ & Eq. (14) & 740.25 & 784.98 \\
\hline Transverse tensile strength $\left(Y_{t}\right)$ & Eq. (30) & 121.62 & 75.20 \\
\hline Transverse compressive strength $\left(Y_{c}\right)$ & Eq. (32) & 75.05 & 186.22 \\
\hline Longitudinal compressive strength & Eqs. (15, 19, 22) & 96.98 & 731.94 \\
$\left(X_{c}\right)$ & Lo-Chim (Eq. 23) & 547.51 & \\
& Budiansky (Eq. 24) & 622.22 & \\
& Wilczynski (Eq. 25) & 740.25 & 91.22 \\
\hline In-plane shear strength $(S)$ & Eq. (34) & 29.82 & \\
& Tsai (Eq. 35) & 71.54 & \\
& King (Eq. 37) & 148.49 & \\
\hline
\end{tabular}

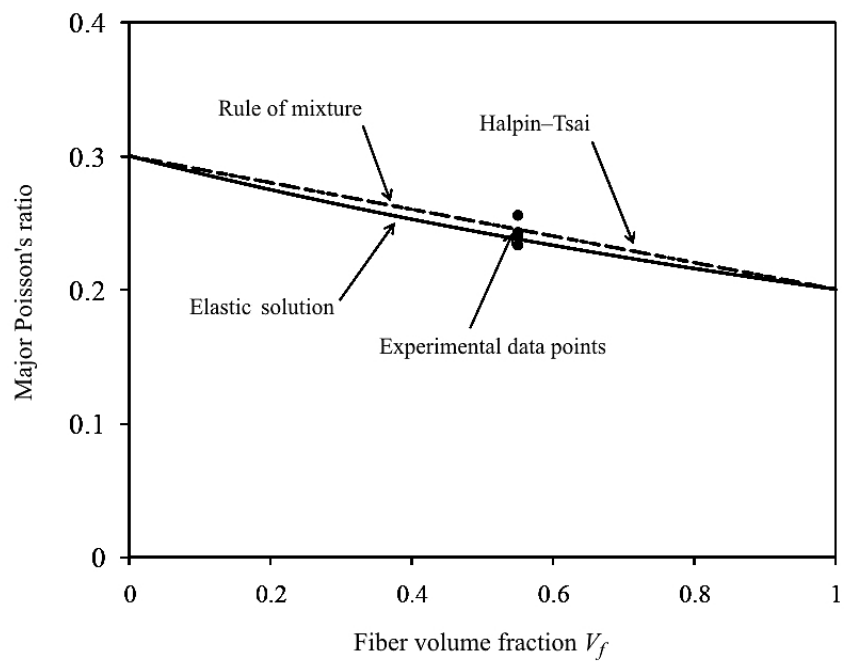

Fig. 7. Theoretical values of major Poisson's ratio as a function of fiber volume fraction compared with experimental values for unidirectional glass/epoxy lamina at room temperature. 
Conclusions. In order to evaluate mechanical properties of UD lamina at room temperature and $-60^{\circ} \mathrm{C}$, instead of direct examination of UD composites, individual properties of the fiber and matrix at room temperature and $-60^{\circ} \mathrm{C}$ were determined experimentally. Then, by using different micromechanical models, mechanical properties (including four elastic moduli and five strengths) of UD composites were predicted. The present research was focused on a unidirectional continuous fiber-reinforced lamina. This is because it forms the basic building block of a composite structure, which is generally made of several unidirectional lamina stacked at various angles. Based on the present study and the results obtained by experiments, the following conclusions can be drawn:

1. Mechanical properties of fiber and matrix change with decreasing temperature to $-60^{\circ} \mathrm{C}$. However, changes in mechanical properties of epoxy matrix are much higher than those of glass fiber. Therefore, the role of matrix in changing the mechanical properties of composites under low temperature is more critical than that of glass fiber.

2. The strength parameters for a UD lamina are much harder to predict than the stiffnesses because the strengths are more sensitive to the material and geometric non-homogeneities, fiber-matrix interface, fabrication process and environmental conditions.

3. For elastic moduli, the mechanics of material approach predicts the lower bound of all four elastic moduli at room temperature, while the Halpin-Tsai model estimates the upper bound of each elastic modulus. Among all models, elastic solution has the best fit with available experimental data for fiber volume fraction of $55 \%$ at room temperature and $-60^{\circ} \mathrm{C}$.

4. Several factors may contribute to discrepancy of experimental and predicted data, including: irregular spacing of fibers causing premature failure in matrix-rich area; non-perfect bonding between fibers and the matrix and poor alignment of fibers.

5. Predicting transverse tensile and in-plane shear strengths of UD lamina is quite complicated. Under transverse tensile and shear loadings, some factors other than the individual properties of the fiber and matrix are important. These include the bond strength between the fiber and the matrix, the present of voids and the present of residual stresses due to thermal expansion mismatch between the fibers and matrix.

Appendix. The transverse Young modulus in elasticity model can be found as follows:

$$
E_{2}=2\left(1+v_{23}\right) G_{23} \text {. }
$$

The transverse Poisson's ratio $v_{23}$ is given by

$$
v_{23}=\frac{K^{*}-m G_{23}}{K^{*}+m G_{23}},
$$

where

$$
m=1+4 K * \frac{v_{12}^{2}}{E_{1}} .
$$


The bulk modulus $K^{*}$ of the composite under longitudinal plane strain is

$$
K^{*}=\frac{K_{m}\left(K_{f}+G_{m}\right) V_{m}+K_{f}\left(K_{m}+G_{m}\right) V_{f}}{\left(K_{f}+G_{m}\right) V_{m}+\left(K_{m}+G_{m}\right) V_{f}} .
$$

The bulk modulus $K_{f}$ of the fiber under longitudinal plane strain is

$$
K_{f}=\frac{E_{f}}{2\left(1+v_{f}\right)\left(1-2 v_{f}\right)} .
$$

The bulk modulus $K_{m}$ of the matrix under longitudinal plane strain is

$$
K_{m}=\frac{E_{m}}{2\left(1+v_{m}\right)\left(1-2 v_{m}\right)} .
$$

The transverse shear modulus $G_{23}$ is given by the acceptable solution of the quadratic equation:

$$
A\left(\frac{G_{23}}{G_{m}}\right)^{2}+2 B\left(\frac{G_{23}}{G_{m}}\right)+C=0,
$$

where

$$
\begin{gathered}
A=3 V_{f}\left(1-V_{f}\right)^{2}\left(\frac{G_{f}}{G_{m}}-1\right)\left(\frac{G_{f}}{G_{m}}+\eta_{f}\right) \\
+\left[\frac{G_{f}}{G_{m}} \eta_{m}+\eta_{f} \eta_{m}-\left(\frac{G_{f}}{G_{m}} \eta_{m}-\eta_{f}\right) V_{f}^{3}\right]\left[V_{f} \eta_{m}\left(\frac{G_{f}}{G_{m}}-1\right)-\left(\frac{G_{f}}{G_{m}} \eta_{m}+1\right)\right], \\
B=-3 V_{f}\left(1-V_{f}\right)^{2}\left(\frac{G_{f}}{G_{m}}-1\right)\left(\frac{G_{f}}{G_{m}}+\eta_{f}\right)+\frac{V_{f}}{2}\left(\eta_{m}+1\right)\left(\frac{G_{f}}{G_{m}-1}\right) \\
\times\left[\frac{G_{f}}{G_{m}}+\eta_{f}+\left(\frac{G_{f}}{G_{m}} \eta_{m}-\eta_{f}\right) V_{f}^{3}\right]+\frac{1}{2}\left[\frac{G_{f}}{G_{m}} \eta_{m}+\left(\frac{G_{f}}{G_{m}}-1\right) V_{f}+1\right] \\
\times\left[\left(\eta_{m}-1\right)\left(\frac{G_{f}}{G_{m}}+\eta_{f}\right)-2\left(\frac{G_{f}}{G_{m}} \eta_{m}-\eta_{f}\right) V_{f}^{3}\right] \\
+\left[\frac{G_{f}}{G_{m}}+\eta_{f}+\left(\frac{G_{f}}{G_{m}} \eta_{m}-\eta_{f}\right) V_{f}^{3}\right]\left[\eta_{m} \frac{G_{f}}{G_{m}}+\left(\frac{G_{f}}{G_{m}}-1\right) V_{f}+1\right]
\end{gathered}
$$




$$
\eta_{m}=3-4 v_{m}, \quad \eta_{f}=3-4 v_{f} \text {. }
$$

Then, using Eqs. (A1)-(A6), the transverse Young modulus can be calculated.

\section{Резиме}

Розрахунок міцності однонаправленого композита при різних типах навантаження в умовах кімнатної температури $\mathrm{i}-60^{\circ} \mathrm{C}$ проводиться за допомогою аналітичних моделей з урахуванням мікромеханічних характеристик композита. На відміну від стандартних методів, що базуються на результатах випробувань зразків з однонаправленого композита, в даній роботі проводиться вимірювання мікромеханічних характеристик скловолокон і епоксидної матриці. За допомогою різних аналітичних моделей виконано розрахунок чотирьох різних модулей пружності і характеристик міцності за кімнатної температури $\mathrm{i}-60^{\circ} \mathrm{C}$. Із метою верифікації результатів розрахунків проведено експериментальні дослідження. Показано, що найкращий розрахунок модулей пружності однонаправленого композита за кімнатної і низької температур забезпечує використання пружної моделі. Отримано хорошу відповідність між розрахунковими й експериментальними даними щодо механічних характеристик цього матеріалу при досліджуваних температурах.

1. Q. Q. Liang, B. Uy, M. A. Bradford, and H. R. Ronagh, "Ultimate strength of continuous composite beams in combined bending and shear," J. Constr. Steel Res., 60, 1109-28 (2004).

2. Z. M. Huang, "Micromechanical prediction of ultimate strength of transversely isotropic fibrous composites," Int. J. Solids Struct., 38, 41474172 (2001).

3. N. K. Naik and R. S. Kumar, "Compressive strength of unidirectional composites: evaluation and comparison of prediction models," Compos. Struct., 46, 299-308 (1999).

4. C. T. Sun and A. W. Jun, "Compressive strength of unidirectional fiber composites with matrix non-linearity," Compos. Sci. Technol., 52, 577-587 (1994).

5. A. P. Wilczynski, "Longitudinal compressive strength of a unidirectional fibrous composite," Ibid, 45, 37-41 (1992).

6. Z. M. Huang, "Simulation of the mechanical properties of fibrous composites by the bridging micromechanics model," Composites, Part A, 32, 143-172 (2001).

7. T. R. King, D. M. Blackketter, D. E. Walrath, and D. F. Adams, "Micromechanics prediction of the strength of carbon fiber/epoxy matrix composites: The influence of the matrix and interface strengths," J. Compos. Mater., 26, No. 4, 558-573 (1992).

8. N. Carbajal and F. Mujika, "Determination of compressive strength of unidirectional composites by three-point bending tests," Polymer Test., 28, 150-156 (2009). 
9. K. H. Lo and E. S. M. Chim, "Compressive strength of unidirectional composites," J. Reinforc. Plastics Compos., 11, 838-896 (1992).

10. P. P. Camanho, C. G. Davila, S. T. Pinho, et al., "Prediction of in situ strengths and matrix cracking in composites under transverse tension and in-plane shear," Composites, Part A, 37, 165-176 (2006).

11. H. Hatta, K. Goto, and T. Aoki, "Strengths of $\mathrm{C} / \mathrm{C}$ composites under tensile, shear, and compressive loading: Role of interfacial shear strength," Compos. Sci. Technol., 65, 2550-2562 (2005).

12. A. W Kaw, Mechanics of Composite Materials, Taylor \& Francis Group (2006), ISBN: 978-0-8493-1343-1.

13. B. W. Rosen, Mechanics of Composite Strengthening in Fiber Composite Materials, American Society for Metals (1965), pp. 37-75.

14. B. Budiansky, "Micromechanics," Comput. Struct., 16, 3-12 (1983).

15. B. Budiansky and N. A. Fleck, "Compressive failure of fiber composites," J. Mech. Phys. Solids, 41, 183-211 (1993).

16. S. W. Tsai, Introduction to Composite Materials, Technomic Publishing Company (1980), ISBN: 0-87762-288-4. 